Society for the Anthropology of Work • Essential Labor

\title{
Essentializing Labor \\ Before, During, and After \\ COVID-19
}

Deepa Das Acevedo

Published on: May 06, 2020

DOI: 10.21428/1d6be30e.5bf00008

License: Creative Commons Attribution 4.0 International License (CC-BY 4.0). 
The United States regulates work via a series of binaries. There are employees and independent contractors; full-time and part-time workers; nonexempt employees and exempt employees, covered individuals and noncovered individuals, and so on. A primary task of a labor and employment law professor, which I am, is to help aspiring attorneys learn the factors and circumstances that will lead judges to slot workers into any one of these conceptual categories, frequently with momentous consequences for both the giver and recipient of work. A primary task of a legal anthropologist, which I also am, is to try and understand how categories like these take on meaning, are contested, or are reified through encounters with various forms of corporate and state power. These two obligations are often at odds with one another-memorizing a seven-factor test for employee classification is hardly conducive to problematizing the test, or the use of classification tests writ large-but they have come into unexpected alignment with the emergence, or so it seems, of a brand-new binary in the regulation of work: essential versus nonessential labor.

Essential work and its opposite are everywhere these days-and, as with most concepts that achieve instant omnipresence, there is precious little clarity about what these terms mean. In California, where I have family, the State Public Health Officer created a list of thirteen sectors [PDF] a list of thirteen sectors employing essential workers and detailing the tasks that are considered essential as well as guidelines for performing them. In Illinois, where I lived for many years, the governor's stay-athome order designated both essential activities (e.g., food production, distribution, and sale) and essential businesses and operations (e.g., stores that sell groceries and medicine). In Alabama, where I am now, the governor took a similar route, although here the list of essential activities and businesses $[\mathrm{PDF}]$ is over twice as long as its nonessential counterpart. These lists overlap enough to suggest coherence and diverge enough to make coherence seem fanciful. And, as if this were not confusing enough, many states have allowed businesses to determine for themselves whether or not they are essential, which is why workers at pool supply stores, craft stores, and video game stores have been considered essential.

What gets lost in the making and interpreting of these lists is the fact that essentiality is not at all new to the way we conceptualize and regulate labor in the United States. COVID-19 may have created a new category of work that is called "essential," but it has not introduced a new way of thinking about work - far from it. We have always allocated protections and obligations based on the degree to which a particular job is considered essential. All that has changed is the referent: essential to whom?

For the most part before (and, in all likelihood, after) the pandemic, the United States has considered work to be essential when it is essential to the employer. The most important binary in U.S. work law, employee versus independent contractor, reflects this attitude: most of the tests used to sort workers into one of these two categories consider, as one factor, the degree to which the work that is done is 
essential to the employer's business. The Internal Revenue Service (IRS) examines "services provided as key activity of the business." Courts often ask "the extent to which the service rendered is an integral part of the alleged employer's business." In California, after the 2019 passage of Assembly Bill $\underline{5}$, courts must consider whether "the service is performed outside the usual course of business of the employer."

Each of these examples comes from a different test used to draw the distinction between employee and independent contractor. The IRS uses the common law or control test, the language about services being "integral" comes from a well-known interpretation of the economic realities test, and California's $A B-5$ codified what is widely called the $A B C$ test. The tests are supposed to be distinct and to produce distinct results, but as these brief excerpts suggest (and as decades of employment law scholarship has argued), they have strong similarities in form and consequence. mong other things, although none of them use the word "essential," they all ask regulators to consider just how important a worker's labor is to the employer. Moreover, this factor is usually more heavily weighted than others when regulators try to determine whether a given worker is or is not an employee.

That determination matters a great deal because employees benefit from the full range of benefits and protections offered to workers in this country: among other things, they are eligible for minimum wage and overtime pay, they are protected against certain forms of workplace discrimination, they have the right to engage in collective activity without penalty, and (except for special circumstances like those defined by the Families First Coronavirus Response Act) they have the right to job protection when they take family or medical leave. None of these applies to independent contractors.

We can see the dynamics of essentiality at an even deeper level of employment law, in the one question that most worker classification disputes boil down to: does the employer control the means and manner in which the worker performs their tasks? This is the core of the control test, but it is also a factor in the economic realities and ABC tests (as well as others that float around the work law universe-lawyers like their tests). Most labor and employment law scholars bemoan the extent to which this one question has become the linchpin of classification analysis, because it can be easily gamed by employers looking to categorize their workers as independent contractors and reap the accompanying financial and administrative benefits (e.g., Tomassetti 2014-2015). But this emphasis on the means and manner of production is, in effect, just another way of asking whether a particular task is essential to the employer.

To see why, think back to a widely read New York Times piece from 2017 that compared two women who had "cleaned offices for one of the most innovative, profitable, and all-around successful companies in the United States"-Gail Evans at Kodak in the early 1980s, and Marta Ramos at Apple today. The piece underscored how employers today are more likely to spin off business functions that they consider extraneous to their core mission and competencies-like building maintenance-and detailed the 
mostly negative impact this has on workers like Ramos, who have less job security and are shut out from the benefits and opportunities for upward mobility that the company whose buildings they clean offers to its own employees. Put differently, Apple does not control the means and manner in which its offices are cleaned (it simply specifies end results that the contractor must satisfy) because it does not consider building maintenance to be an essential task. As a result, Ramos and other subcontracted workers do not benefit from the various perks offered to Apple employees.

For several weeks now, thanks to COVID-19, essential labor has meant something different. Rather than referencing labor that is essential to an employer's core business functions and that is therefore likely to be performed by someone classified as an employee, essential labor now refers to tasks that are essential to society. Some of these tasks are predictable under any circumstances and are particularly during a health crisis: medical professionals, pharmacists, emergency and first-response services, grocers and other food distributors. Others-especially gig workers-are a less obvious inclusion, since this type of work (at least in its algorithmically mediated form) is itself a recent development. Although some urban transportation officials likely considered Uber and Lyft to be indispensable elements of contemporary life even before the onset of the pandemic, most government actors-indeed, most nongovernmental actors - likely did not consider them, or Instacart shoppers, or Shipt workers, to be essential labor.

That has all changed. Now, the value of an Instacart shopper who is willing to brave grocery stores in your stead or of an Uber driver who will take your elderly mother to the hospital has risen astronomically, to say nothing of the Amazon warehouse worker who is not a conventional gig worker but who labors under markedly similar conditions. These people make it possible for many of us to live the way we do in the places we do, and so they are included in most of the lists promulgated by state officials delineating who may and may not work. They are essential to society despite the fact that even now, in almost every U.S. state and locality, they are not considered essential enough to their (putative) employers to be viewed as losing the level of freedom that comes with formal employee status (Das Acevedo 2018). When Uber CEO Dara Khosrowshahi wrote to President Trump to ask that his company's drivers be included in any federal stimulus package, he also made sure to ask that this not affect their classification status and to reiterate the need for a third category (neither independent contractor nor employee) into which gig workers could be slotted.

I have argued that the conversation about essential labor has focused on the adjective-essentialinstead of the prepositional phrase-essential to whom - that hovers unacknowledged in the background. As a result, essential labor seems much newer, conceptually and legally, than it actually is. All we are seeing is a difference in referent, from the employer to society at large. Does this matter?

Yes and no. On the one hand, the rise of essential labor as a category of regulation and analysis is unlikely to make much of a lasting difference to essential workers themselves. If anything, being 
labeled essential right now leaves individuals who were not already considered employees considerably worse off in the short term. This is because being essential under the once-and-future model meant that a worker received some benefits in return for their loss of freedom. Today, being essential simply means that a worker is obliged to continue working under the riskiest of conditions through the greatest public health crisis of their life.

On the other hand, the stability that underlies this new way of talking should reveal some of the fault lines in the ways that we study and regulate work. Work law has long been faulted for the way it fails to seriously account for differences of race, sex, gender, and class, among other things: it pretends that the consequences of being essential or not fall equally on everyone. Work scholarship, meanwhile, frequently overlooks this failing of work law, as well as its obsession with prepositional over adjectival understandings of labor, even as it does a fantastic job of teasing out those complexities itself through careful and nuanced ethnographies. A shift in both realms may prove to be the most important lesson that essential labor teaches us about the world of work.

\section{Author Bio}

Deepa Das Acevedo is Assistant Professor of Law at the University of Alabama School of Law, having received her JD and $\mathrm{PhD}$ in anthropology from the University of Chicago. She has conducted ethnographic research on gig work regulation in the United States, and she teaches courses on employment law, employee benefits, and legal anthropology. Her edited volume, Beyond the Algorithm: Qualitative Insights for Gig Work Regulation, is forthcoming with Cambridge University Press.

\section{References}

Das Acevedo, Deepa. 2018. "Unbundling Freedom in the Sharing Economy." Southern California Law Review 91(5): 793-838.

Tomassetti, Julia. 2014-2015. “The Contracting-Producing Ambiguity and the Collapse of the Means/Ends Distinction in Employment." South Carolina Law Review 66(2): 315-99.

\section{Preview Image}

Courtesy of Gilbert Mercier. 